\title{
Comparative Study on Aroma Volatiles, Organic Acids, and Sugars of Ambul Banana (Musa acuminata, AAB) Treated with Induced Ripening Agents
}

\author{
S. D. T. Maduwanthi (iD) and R. A. U. J. Marapana \\ Department of Food Science and Technology, University of Sri Jayewardenepura, Nugegoda, Sri Lanka \\ Correspondence should be addressed to S. D. T. Maduwanthi; tharaka@sci.sjp.ac.lk
}

Received 6 June 2019; Revised 25 August 2019; Accepted 31 August 2019; Published 10 October 2019

Academic Editor: Márcio Carocho

Copyright ( 2019 S. D. T. Maduwanthi and R. A. U. J. Marapana. This is an open access article distributed under the Creative Commons Attribution License, which permits unrestricted use, distribution, and reproduction in any medium, provided the original work is properly cited.

\begin{abstract}
The present study was conducted to investigate effect of induced ripening agents on aroma profile, organic acids and sugars of Ambul banana (Musa acuminata, AAB). Mature green bananas that are in same maturity stage were subjected to $1000 \mathrm{ppm}$ ethephon and $1000 \mathrm{ppm}$ acetylene and kept at $20^{\circ} \mathrm{C}, 80-85 \% \mathrm{RH}$ for ripening. Aroma profile was analyzed by SPME-GC-MS, while organic acids and sugars were tested by HPLC. Naturally ripened banana was found to be more aromatic than acetylene- and ethephon-treated banana having highest number of volatile compounds (27) and high level of esters (65\%). Malic acid, citric acid, and oxalic acids were significantly low in treated bananas compared to naturally ripened bananas. Glucose and fructose, which are major types of sugars in ripe banana flesh, were significantly low in acetylene-treated banana, while sucrose was not detected in both ethephon- and acetylene-treated samples at fully yellow stage. Although ethephon and acetylene trigger the ripening process, they lead to poor aroma profile and lower levels of organic acids and sugars in flesh of banana.
\end{abstract}

\section{Introduction}

Banana is a very popular fruit in the world, which belongs to the Eumusa section of genus Musa from the family Musaceae. When considering its importance as a food crop, it is considered as the most important crop after rice, wheat, and maize [1]. Bananas are of two types: dessert/table bananas, which are consumed raw as a dessert, and cooking type bananas, which are referred as plantains. There are 300-500 banana cultivars all over the world, while most popular cultivars are Musa cavendishi, Musa paradisiaca, and Musa sapientum $[2,3]$.

Banana is a climacteric fruit and after harvest, it exhibits a respiratory peak during natural ripening [4]. They are often harvested at mature green preclimacteric stage and induced to ripen using artificial ripening agents to obtain fruits with a same maturity stage and uniform peel colour [5]. The most popular method used in developed countries is exposing banana to ethylene gas in ripening rooms under controlled temperature and humidity [6]. Alternatively to ethylene gas, chemicals such as ethephon (2-chloroethylphosphonic acid) that can generate ethylene is widely used as a commercial ripening agent in developing countries. Acetylene, which is an ethylene analogue, can enhance fruit ripening [7]. In most developing countries, acetylene is produced using calcium carbide, which is prohibited due to its toxicity to humans [8]. Many research studies have reported that chemicals such as ethanol, methanol, propylene, methyl jasmonate, and ethylene glycol also can instigate fruit ripening [9].

Fruit ripening is a highly coordinated, genetically programmed, and an irreversible process involving a series of physiological, biochemical, and organoleptic changes such as increased respiration, ethylene production, chlorophyll degradation, biosynthesis of carotenoids, anthocyanins, essential oils, flavour, and aroma compounds, and activation of cell wall-degrading [10]. Artificial ripening agents affect nutritional quality of fruits $[9,11,12]$, and many studies show that artificially ripened fruits have significant differences in peel colour, aroma, flavour, and sensory quality when compared to naturally ripened fruits [13-15]. This 
study was conducted to analyze the effect of ethephon and acetylene on different biochemical attributes of banana (Musa acuminata, AAB).

\section{Methodology}

2.1. Plant Material. Banana (Musa acuminata, AAB) were harvested at green mature stage from an orchard in Dankotuwa, Sri Lanka, and immediately transported to the laboratory with a minimum physical stress. Banana hands were separated and washed thoroughly with water. Peel colour was measured using Chroma meter (Lovibond LC 100, China), and texture was measured using texture analyzer (CT3 Brookfield, USA) in each hand with six replicate measurements. The values were subjected to analysis of variance using MINITAB 17 software under 0.05 significant level and the hands that did not show significant difference were taken for treatments.

2.2. Ethephon Treatment. The treatment was designed referring to Adane et al. [16] with modifications. Fifty milliliters of $1000 \mathrm{ppm}$ ethephon (2-chloroethylphosphonic acid) (Sigma, $98.6 \%$ ) was prepared and mixed with $50 \mathrm{ml}$ of $1000 \mathrm{ppm} \mathrm{NaOH}$ in a closed chamber where $1 \mathrm{~kg}$ of banana was placed. Samples were exposed to the ethylene gas emitted from the above solution for 24 hours. Treated samples were stored under $20^{\circ} \mathrm{C}$ and $80-85 \%$ relative humidity $(\mathrm{RH})$.

2.3. Acetylene Treatment. The treatment was conducted referring to Thompson and Seymour [5] with modifications. Bananas were exposed to $1000 \mathrm{ppm}$ acetylene using $3.07 \mathrm{~g}$ of purified calcium carbide (Sigma Aldrich, $80 \%$ ) per $1 \mathrm{~kg}$ of banana. Samples were exposed to it for 24 hours. Treated samples were stored under $20^{\circ} \mathrm{C}$ and $80-85 \%$ relative humidity (RH).

\section{General Analysis}

3.1. Aroma Profile. Aroma profile was analyzed at stage 6 in each treatment by solid-phase microextraction (SPME) according to the method given by Bugaud and Alter [17] with some modifications. Five grams of banana flesh was homogenized with $5 \mathrm{ml}$ of distilled water. Then $1 \mathrm{~g}$ from the homogenized mixture was inserted in to a $20 \mathrm{ml}$ SPME vial. The sample was kept in a water bath at $60^{\circ} \mathrm{C}$ for $10 \mathrm{~min}$ for equilibrium. Aroma compounds were adsorbed using SPME fiber (Supelco, 50/30 $\mu \mathrm{m}$ divinylbenzene/Carboxen on polydimethylsiloxane on a $2 \mathrm{~cm}$ stable flex fiber) by exposing the fiber into headspace of the sample for $10 \mathrm{~min}$ at $60^{\circ} \mathrm{C}$.

Gas chromatograph mass spectrophotometric (GC-MS) analyses were carried out using Agilent 7890A coupled with Mass Spectrophotometer (5975C). Volatile compounds were separated on a DB-225MS (Agilent) capillary column $(30 \mathrm{~m} \times 250 \mu \mathrm{m} \times 0.25 \mu \mathrm{m})$. Helium was used as carrier gas at a constant flow rate $1 \mathrm{ml} / \mathrm{min}$. Samples were manually injected to $\mathrm{GC}$ at $240^{\circ} \mathrm{C}$ in split less mode for $5 \mathrm{~min}$. The temperature program was started with the oven temperature at $40^{\circ} \mathrm{C}$, then $2^{\circ} \mathrm{C} / \mathrm{min}$ to $70^{\circ} \mathrm{C}$, hold at $70^{\circ} \mathrm{C}$ for $5 \mathrm{~min}$, then up to $170^{\circ} \mathrm{C}$ by $5^{\circ} \mathrm{C} / \mathrm{min}$, then $50^{\circ} \mathrm{C} / \mathrm{min}$ up to $220^{\circ} \mathrm{C}$, and finally maintained at $220^{\circ} \mathrm{C}$ for $5 \mathrm{~min}$.

Compounds were tentatively identified by comparing the results obtained with the reference mass spectra from NIST library (NIST 08) using the criterion of at $80 \%$ similarity for the mass spectra. Relative abundance (RA) of each compound was calculated using total sum normalization using the following formula:

$$
\mathrm{RA} \%=\frac{\text { area of the peak }}{\text { sum of areas of all peaks }} \times 100 \% \text {. }
$$

3.2. Organic Acids. Organic acid analysis was done according to the method described by Liu et al. [18] with few modifications. Sample preparation was done by homogenizing $5 \mathrm{~g}$ of fruit pulp with $10 \mathrm{ml}$ of double distilled water. Homogenate was centrifuged $6000 \mathrm{rpm}$ for 10 minutes. The supernatant was filtered through $0.45 \mu \mathrm{m}$ nylon filters, and the filtrate was used for HPLC determination.

The chromatographic separation was carried out using the Agilent-1260-Infinity HPLC system (Agilent, Germany). The column was Agilent Eclipse Plus C18, $5 \mu \mathrm{m} 4.6 \times 250 \mathrm{~mm}$. Mobile phase consisted of $97 \%$ dipotassium hydrogen phosphate buffered at $\mathrm{pH} 2.6$ with orthophosphoric acid and 3\% methanol $(100 \%)$. The flow rate was $1.0 \mathrm{~mL} / \mathrm{min}$ at $30^{\circ} \mathrm{C}$. The detection was carried out at $210 \mathrm{~nm}$. Results were expressed as milligram per $100 \mathrm{~g}$ of fresh weight.

Quantifications were done using standard curves prepared using external standards of malic acid, oxalic acid, tartaric acid, and citric acid supplied by Sigma-Aldrich (USA).

3.3. Sugars. The organic acid analysis was done according to the method described by Ma et al. [19] with a few modifications. Sample preparation was done by homogenizing $5 \mathrm{~g}$ of fruit pulp with $10 \mathrm{ml}$ of double distilled water. Homogenate was centrifuged at $6000 \mathrm{rpm}$ for 10 minutes. The supernatant was filtered through $0.45 \mu \mathrm{m}$ nylon filters, and the filtrate was used for high-performance liquid chromatography (HPLC) determination. The chromatographic separation was carried out using the Agilent-1260-Infinity HPLC system (Agilent, Germany) equipped with quaternary gradient pump, refractive index (RI) detector, and thermostated column compartment. Chromatographic separation was achieved with Zorbax NH2 $(4.6 \mathrm{~mm} \times 250 \mathrm{~mm}, 5 \mu \mathrm{m}$, Agilent USA) analytical HPLC column. Mobile phase consisted of acetonitrile: water: $70: 30 \mathrm{v} / \mathrm{v}$ (isocratic) with a flow rate was $1.2 \mathrm{~mL} / \mathrm{min}$. Injection volume was $10.0 \mu \mathrm{L}$, and column compartment was thermostated at $30^{\circ} \mathrm{C}$. Results were expressed as mg per $100 \mathrm{~g}$ of fresh weight.

Quantifications were done using standard curves prepared using external standards of sucrose, maltose, fructose, and glucose obtained by Sigma-Aldrich (USA).

3.4. Statistical Analysis. Data obtained were subjected to analysis of variance under $95 \%$ confidence level using MINITAB 17. 


\section{Results and Discussion}

4.1. Efficiency of Ripening Agents. Table 1 shows peel colour, firmness, and stage of ripeness in each treatment in 48 hours intervals. Banana treated with $1000 \mathrm{ppm}$ ethephon and acetylene turned to fully yellow (Stage 6) after 2 days, while the natural ripening process took 8 days to turn the fruit to stage 6 . The peel colour was highest in acetylene-treated fruits at stage 6 , which was $50.7 \pm 3.75 \mathrm{C}^{*}$, while $42.23 \pm 6.55$ and $46.87 \pm 2.65 \mathrm{C}^{*}$ in ethephon and natural ripening, respectively. However, firmness was $350 \pm 46 \mathrm{~g}$ in naturally ripened banana at stage 6 when artificially ripened banana recorded higher values than that.

4.2. Aroma Volatiles. Table 2 shows aroma compounds detected by SPME-GC-MS technique on DB-225MS column in ethephon-treated banana, acetylene-treated banana, and naturally ripened banana at stage 6 . Total number of aroma compounds detected in naturally ripened banana was 27 when 16 and 15 compounds were detected, respectively, in ethephon- and acetylene-treated banana. The results further confirm the findings of Sonmezdag et al. [13], indicating that naturally ripened banana is more aromatic than artificially ripened banana. According to Mayr et al. [20], approximately 250 volatile compounds have been detected in banana at different stages of ripeness and different varieties. However, the number of compounds that are really odour-active is less than $40[17,21]$. Since SPME technique isolates high and medium volatile compounds, the total number of aroma compounds detected here was 35. Thirteen compounds out of this 35 including ethyl acetate, propyl butanoate, 2-methylpropyl 3-methylbutanoate, pentan-2-yl butanoate, 3-methylbutyl 2-methylbutanoate, 2-methylpropyl hexanoate, 3-methylbutyl hexanoate, decanal, 2methyl-1-propanol, Z-4-dodecenol, 2-methyl-1-butanol, 1ethylcyclohexene, and 2,4-ditert-butylphenol were detected only in naturally ripened samples. Methyl butyl esters were the most abundant volatile component at stage 6 of all samples as found in many studies $[13,17,22]$.

When comparing relative abundance percentage (RA\%) of total esters, aroma profile of naturally ripened banana consists of $65.0 \%$ of esters, whereas in ethephon-treated samples, it was $35.0 \%$. The lowest percentage of esters was noted in acetylenetreated samples as there was only $25.4 \%$ of esters. This emphasizes the fact that ester accumulation during ripening is closely related with ethylene biosynthesis [13].

3-Methylbutyl butanoate was the most abundant volatile compound in naturally ripened samples, accounting for $24.5 \%$ of RA\%. However, 3-methylbutyl acetate was the most abundant component in treated samples accounting for $11.9 \%$ and $10.6 \%$ of RA, respectively, in ethephon- and acetylenetreated samples. According to Pino and Febles [22], 3methylbutyl acetate (ripe banana), 3-methylbutyl 3-methylbutanoate (fruity banana like), and 3-methylbutyl butanoate (fruity banana peel) are key compounds as well as the most abundant compounds in banana aroma. Accordingly, in naturally ripened samples, these three esters were recorded as the most abundant compounds accounting for $8,12.2$, and
$24.5 \%$ of RA\%, respectively. However, 3-methylbutyl 3methylbutanoate was detected at significantly minor percentages ( $0.8 \%$ in ethephon-/acetylene-treated samples). 3methylbutyl butanoate was detected in significantly low percentages $(0.2 \%$ in acetylene-treated bananas). Ethyl acetate, which is responsible for fruity flower aroma according to Bugaud and Alter [17], is considered as an important odouractive compound in banana aroma profile [22]. Ethyl acetate was absent in ethephon- and acetylene-treated samples.

The percentage of aldehydes was highest (14.2\%) in acetylene-treated banana, while the lowest $(2.1 \%)$ was found in naturally ripened banana. This is in contrast with the findings of Vermeir et al. [23] and Sonmezdag et al. [13], where it was recorded that the aldehyde contents of naturally ripened banana were much higher than those of the artificially ripened banana. (E)-2-hexenal can be considered as the major aldehyde present in banana aroma and it is also consistent with earlier research work $[13,22,24,25]$. However, RA\% of $(E)-2$ hexenal was significantly low in naturally ripened samples when compared to treated samples.

Alcoholic compounds are decreased during ripening process $[13,26]$. None of the alcoholic compounds were detected in ethephon- and acetylene-treated banana.

4.3. Organic Acids. Organic acids are natural compounds available in banana flesh contributing to the acidic nature, which is an important quality parameter in banana. During fruit ripening, organic acid levels decrease along with accumulation of sugars in fruit flesh [27]. As in many climacteric fruits, malic acid and citric acid are the most abundant organic acids in banana flesh (Table 3 ).

According to Figure 1, citric acid is the most abundant organic acid at fully green stage (stage 1), while tartaric acid and oxalic acid were detected in low amounts as $16.1 \pm 2.3$ and $30.8 \pm 1.6 \mathrm{mg} / 100 \mathrm{~g}$, respectively. This record is in contrast with that of Wyman and Palmer [28], where it was found that oxalic acid is the predominant acid at raw stage of banana. This might be due to the difference in the variety since Musa acuminata, AAB, a type of sour banana, was used in the present analysis. Citric acid shows an increasing trend until day 6 (stage 4) where it reaches its peak. The amount of malic acid at stage 1 was $200.83 \pm 2.08 \mathrm{mg} / 100 \mathrm{~g}$ and it increases during ripening, reaches its maximum at day 8 (stage 6 ), and decreases when it reaches overripe stage (stage 7). This behavior of malic acid shows good agreement with Wyman and Palmer [28] and Agravante et al. [29].

Furthermore, it is seen that the variation of malic acid somewhat corresponds with respiration rate of the fruit. It increases up to a point where ripening begins and then declines after that. This behavior was obtained by Harris and Poland [30] as well. Pua et al. [31] further clarified that malic acid accumulation in banana flesh during ripening occurs through glyoxylate cycle, regulated by MaMS-1, which can be induced by ethylene. Simply, it exhibits that exogenous ethylene treatment can also trigger malic acid accumulation in fruit flesh.

Figure 2 represents variation of malic, oxalic, citric, and tartaric acids during the ripening process of naturally 


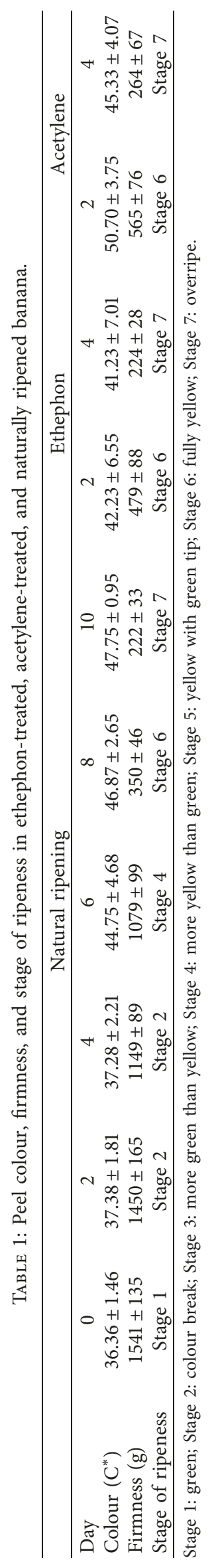


TABLE 2: Volatile compounds detected by SPME at fully yellow stage of banana.

\begin{tabular}{|c|c|c|c|c|c|c|c|c|c|}
\hline \multirow{2}{*}{ Volatile compound } & \multicolumn{3}{|c|}{ Natural ripening } & \multicolumn{3}{|c|}{ Ethephon } & \multicolumn{3}{|c|}{ Acetylene } \\
\hline & & $\begin{array}{c}\text { Relative } \\
\text { abundance (\%) }\end{array}$ & $\begin{array}{c}\text { Peak area } \\
\left(\times 10^{6}\right)\end{array}$ & & $\begin{array}{c}\text { Relative } \\
\text { abundance (\%) }\end{array}$ & $\begin{array}{c}\text { Peak area } \\
\left(\times 10^{6}\right)\end{array}$ & & $\begin{array}{c}\text { Relative } \\
\text { abundance (\%) }\end{array}$ & $\begin{array}{l}\text { Peak area } \\
\left(\times 10^{6}\right)\end{array}$ \\
\hline \multicolumn{10}{|l|}{ Esters } \\
\hline Ethyl acetate & $\mathrm{D}$ & 1.1 & 52.98 & ND & - & - & $\mathrm{ND}$ & - & - \\
\hline Ethyl butanoate & $\mathrm{D}$ & $1.6^{\mathrm{a}}$ & 78.03 & $\mathrm{D}$ & $1.9^{\mathrm{a}}$ & 52.59 & $\mathrm{D}$ & $1.4^{\mathrm{a}}$ & 47.31 \\
\hline Butyl acetate & $\mathrm{D}$ & $0.7^{\mathrm{b}}$ & 36.67 & $\mathrm{D}$ & $3.5^{\mathrm{a}}$ & 93.50 & $\mathrm{D}$ & $2.5^{\mathrm{a}}$ & 82.06 \\
\hline 3-Methylbutyl acetate & $\mathrm{D}$ & $8.0^{\mathrm{a}}$ & 401.43 & $\mathrm{D}$ & $11.9^{\mathrm{b}}$ & 321.53 & $\mathrm{D}$ & $10.6^{\mathrm{c}}$ & 352.10 \\
\hline Propyl butanoate & $\mathrm{D}$ & 0.2 & 9.16 & ND & - & - & ND & - & - \\
\hline 2-Methylpropyl butanoate & $\mathrm{D}$ & $9.7^{\mathrm{a}}$ & 484.15 & $\mathrm{D}$ & $2.2^{\mathrm{b}}$ & 60.28 & $\mathrm{D}$ & $3.6^{\mathrm{b}}$ & 121.55 \\
\hline $\begin{array}{l}\text { 2-Methylpropyl 3- } \\
\text { methylbutanoate }\end{array}$ & $\mathrm{D}$ & 2.0 & 98.06 & ND & - & - & ND & - & - \\
\hline Pentan-2-yl butanoate & $\mathrm{D}$ & 1.1 & 56.18 & ND & - & - & ND & - & - \\
\hline Butyl butanoate & $\mathrm{D}$ & $2.0^{\mathrm{b}}$ & 100.23 & $\mathrm{D}$ & $2.4^{\mathrm{b}}$ & 64.97 & $\mathrm{D}$ & $3.5^{\mathrm{a}}$ & 117.01 \\
\hline Butyl pentanoate & $\mathrm{D}$ & $0.9^{\mathrm{a}}$ & 46.00 & $\mathrm{D}$ & $0.2^{\mathrm{a}}$ & 5.81 & ND & - & - \\
\hline $\begin{array}{l}\text { 3-Methylbutyl 2- } \\
\text { methylbutanoate }\end{array}$ & $\mathrm{D}$ & 0.3 & 16.25 & ND & - & - & ND & - & - \\
\hline $\begin{array}{l}\text { 3-Methylbutyl 3- } \\
\text { methylbutanoate }\end{array}$ & $\mathrm{D}$ & $12.2^{\mathrm{a}}$ & 611.69 & $\mathrm{D}$ & $0.8^{\mathrm{b}}$ & 20.97 & $\mathrm{D}$ & $0.8^{\mathrm{b}}$ & 25.21 \\
\hline 2-Methylpropyl hexanoate & $\mathrm{D}$ & $<0.0$ & 2.02 & ND & - & - & ND & - & - \\
\hline$[(E)$-hex-4-enyl] butanoate & $\mathrm{D}$ & $0.2^{\mathrm{a}}$ & 10.98 & ND & - & - & $\mathrm{D}$ & $0.2^{\mathrm{a}}$ & 7.15 \\
\hline 3-Methylbutyl hexanoate & $\mathrm{D}$ & 0.2 & 8.59 & ND & - & - & ND & - & - \\
\hline 2-Methylpropyl acetate & ND & - & - & $\mathrm{D}$ & $2.6^{\mathrm{a}}$ & 70.57 & $\mathrm{D}$ & $2.2^{\mathrm{a}}$ & 73.18 \\
\hline Hexyl acetate & ND & - & - & $\mathrm{D}$ & $0.3^{\mathrm{a}}$ & 8.10 & $\mathrm{D}$ & $0.2^{\mathrm{a}}$ & 6.78 \\
\hline 3-Methylbutyl butanoate & $\mathrm{D}$ & $24.5^{\mathrm{a}}$ & 1226.02 & $\mathrm{D}$ & $9.0^{\mathrm{b}}$ & 243.30 & $\mathrm{D}$ & $0.2^{\mathrm{c}}$ & 6.56 \\
\hline Hexyl butanoate & $\mathrm{ND}$ & - & & $\mathrm{D}$ & $0.1^{\mathrm{a}}$ & 3.47 & $\mathrm{D}$ & $0.2^{\mathrm{a}}$ & 5.19 \\
\hline [(E)-Hex-4-enyl] pentanoate & $\mathrm{D}$ & 0.3 & 13.92 & ND & - & - & ND & - & - \\
\hline $\begin{array}{l}\text { Propanoic acid, 2-methyl-, 1- } \\
\text { (1,1-dimethylethyl)-2-methyl- } \\
\text { 1,3-propanediyl ester }\end{array}$ & ND & - & - & $\mathrm{D}$ & 0.1 & 2.08 & ND & - & - \\
\hline Total esters (RA\%) & & $65.0 \%$ & & & $35.0 \%$ & & & $25.4 \%$ & \\
\hline \multicolumn{10}{|l|}{ Aldehydes } \\
\hline Hexanal & $\mathrm{D}$ & $0.8^{\mathrm{a}}$ & 39.96 & ND & - & - & $\mathrm{D}$ & $5.3^{\mathrm{b}}$ & 177.85 \\
\hline (E)-2-hexenal & $\mathrm{D}$ & $1.3^{\mathrm{b}}$ & 64.51 & $\mathrm{D}$ & $7.8^{\mathrm{a}}$ & 209.85 & $\mathrm{D}$ & $8.9^{\mathrm{a}}$ & 297.55 \\
\hline Decanal & $\mathrm{D}$ & $<0.0$ & 2.12 & ND & - & - & ND & - & - \\
\hline (E)-3-hexenal & $\mathrm{ND}$ & - & - & $\mathrm{D}$ & 0.3 & 8.35 & ND & - & - \\
\hline Total aldehydes (RA\%) & & $2.1 \%$ & & & $8.1 \%$ & & & $14.2 \%$ & \\
\hline \multicolumn{10}{|l|}{ Alcohols } \\
\hline 2-Methyl-1-propanol & $\mathrm{D}$ & 0.1 & 5.93 & ND & - & - & ND & - & - \\
\hline Z-4-Dodecenol & $\mathrm{D}$ & $<0.0$ & 1.65 & ND & - & - & ND & - & - \\
\hline 2-Methyl-1-butanol & $\mathrm{D}$ & 1.8 & 89.34 & ND & - & - & ND & - & - \\
\hline Total alcohols (RA\%) & & $1.9 \%$ & & & $0.0 \%$ & & & $0.0 \%$ & \\
\hline \multicolumn{10}{|l|}{ Benzenic derivatives } \\
\hline Benzaldehyde & $\mathrm{D}$ & $0.1^{\mathrm{a}}$ & 3.18 & $\mathrm{D}$ & $0.1^{\mathrm{a}}$ & 2.14 & $\mathrm{D}$ & $0.1^{\mathrm{a}}$ & 3.31 \\
\hline 1-Ethylcyclohexene & $\mathrm{D}$ & $<0.0$ & 1.53 & ND & - & - & ND & - & - \\
\hline 2,4-Di-tert-butylphenol & $\mathrm{D}$ & 0.2 & 11.69 & ND & - & - & ND & - & - \\
\hline $\begin{array}{l}\text { 1,2,3-Trimethoxy-5-prop-2- } \\
\text { enylbenzene }\end{array}$ & $\mathrm{D}$ & $0.3^{\mathrm{a}}$ & 17.14 & ND & - & - & $\mathrm{D}$ & $0.3^{\mathrm{a}}$ & 9.83 \\
\hline $\begin{array}{l}\text { Total benzenic derivatives } \\
\text { (RA\%) }\end{array}$ & & $0.6 \%$ & & & $0.1 \%$ & & & $0.4 \%$ & \\
\hline \multicolumn{10}{|l|}{ Ethers } \\
\hline Total ethers (RA\%) & & $0.0 \%$ & & & $0.2 \%$ & & & $0.0 \%$ & \\
\hline $\begin{array}{l}\text { Total number of aroma } \\
\text { compounds detected }\end{array}$ & 27 & & & 16 & & & 15 & & \\
\hline
\end{tabular}

D: detected; ND: not detected; RA (\%): relative abundance (\%). Values bearing different superscript letters within the same row are statistically significant at $95 \%$ confidence level.

ripened, ethephon-treated, and acetylene-treated banana. Similar variation pattern of malic acid can be noted in ethephon- and acetylene-treated banana where malic acid level increases continuously during the ripening process and it reaches peak at the overripe stage. However, when we consider malic acid content at stage 6 (Table 3), malic acid is 
TABLe 3: Organic acids at fully yellow stage.

\begin{tabular}{lccc}
\hline Organic acids & $\begin{array}{c}\text { Natural } \\
\text { ripening }\end{array}$ & Ethephon & Acetylene \\
\hline Malic acid $(\mathrm{mg} / 100 \mathrm{~g})$ & $544.30 \pm 2.80^{\mathrm{a}}$ & $210.88 \pm 1.70^{\mathrm{b}}$ & $340.94 \pm 1.81^{\mathrm{c}}$ \\
Citric acid $(\mathrm{mg} / 100 \mathrm{~g})$ & $341.67 \pm 0.32^{\mathrm{a}}$ & $109.98 \pm 0.40^{\mathrm{b}}$ & $92.94 \pm 1.53^{\mathrm{c}}$ \\
Tartaric acid $(\mathrm{mg} / 100 \mathrm{~g})$ & $60.93 \pm 2.54^{\mathrm{a}}$ & $15.28 \pm 0.35^{\mathrm{b}}$ & $53.33 \pm 2.45^{\mathrm{a}}$ \\
Oxalic acid $(\mathrm{mg} / 100 \mathrm{~g})$ & $57.3 \pm 1.56^{\mathrm{a}}$ & $19.57 \pm 1.04^{\mathrm{b}}$ & $25.43 \pm 2.85^{\mathrm{b}}$ \\
\hline
\end{tabular}

Values bearing different superscript letters within the same row are statistically significant at $95 \%$ confidence level.

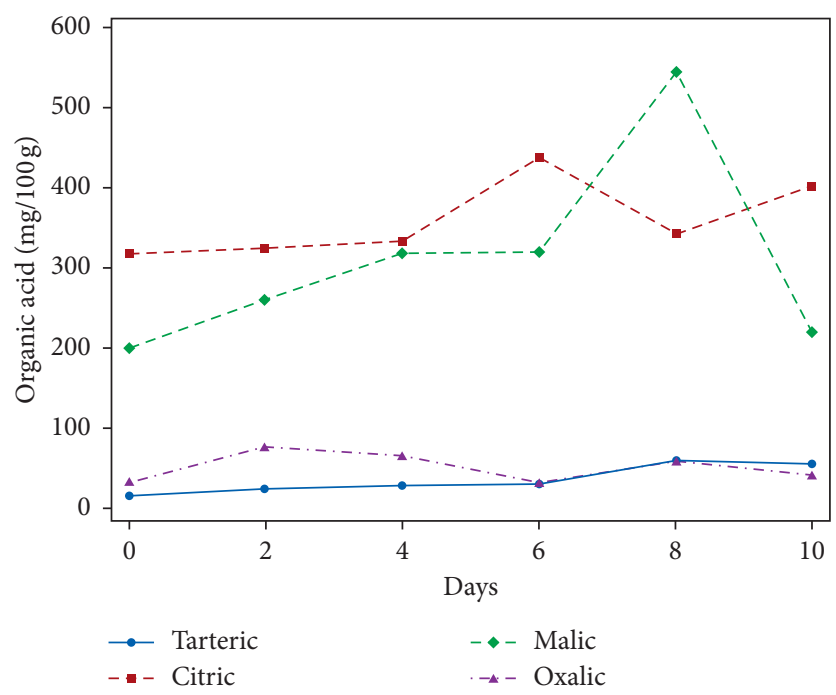

FIgURE 1: Organic acid changes during natural ripening.

significantly high in naturally ripened banana and significantly low in ethephon-treated banana.

Citric acid shows a sudden reduction in first 2 days in both ethephon- and acetylene-treated banana (Figure 2(b)). This may be due to the sudden activation of respiratory climacteric and utilization of citric acid in tricarboxylic acid cycle for respiration [32]. In natural ripening, the similar reduction of citric acid can be seen after stage 4 . Significantly high citric acid level was detected in naturally ripened samples at stage 6 compared to other two samples (Table 3 ).

Oxalic acid is reported as the acid responsible for the astringent taste in raw banana flesh fully or partly [33]. Oxalic acid content increases up to day 4 , after which there is a sudden drop within next two days and rise up again. The reduction of oxalic acid at climacteric rise was noted in the study by Wyman and Palmer [28] as well. This reduction may be due to oxalic acid being utilized as the $\mathrm{CO}_{2}$ source at climacteric rise [34]. In ethephon- and acetylene-treated samples, oxalic acid shows this reduction within first two days indicating the sudden activation of climacteric rise just after the treatments. However, oxalic acid content at stage 6 as shown in Table 2, significantly high in naturally ripened banana.

Tartaric acid increases till stage 6 , reaches its maximum, and reduces at stage 7 in acetylenetreated samples. However, the acid varies in a different manner in ethephon-treated samples where it increases continuously till stage 7 . Nevertheless, tartaric acid content at stage 6 is significantly low in ethephon-treated samples, when compared to other two which can cause low level of total acidity in banana flesh.

4.4. Sugars. During ripening, starch is degraded rapidly, while sugars get accumulated [33]. Well-matured banana contains nearly $20-25 \%$ of starch by fresh weight before ripening [35]. Starch degradation is one of the key mechanisms in banana fruit, which causes softening of the fruit during ripening [10] and it supplies carbon for sucrose synthesis [36]. Under this analysis, fructose, glucose, and sucrose were detected in banana flesh, while maltose was not detected at any stage of ripeness complying with Yang and Ho [37] and Kheng et al. [32]. None of the sugars were detected at fully green stage (Day 0). As Figure 3 depicts, both fructose and glucose showed an increasing trend during natural ripening till the fruit reaches stage 6 (Day 8), while fructose and glucose reduces when it comes to stage 7 . There is a sudden increment in fructose and glucose contents after the treatments of ethephon and acetylene. Ratio of fructose to glucose at all stages of ripeness is close to unity, regardless of the treatment, indicating that the immediate precursor of these sugars is sucrose in all treatments.

Sucrose was detected only in naturally ripened banana at stage 6 (Table 4), and sucrose was not available in treated samples at any stage. This result does not correspond with Seymour [33], Kheng et al. [32], and Lizana [38], where it has been found that sucrose is the predominant sugar at green 


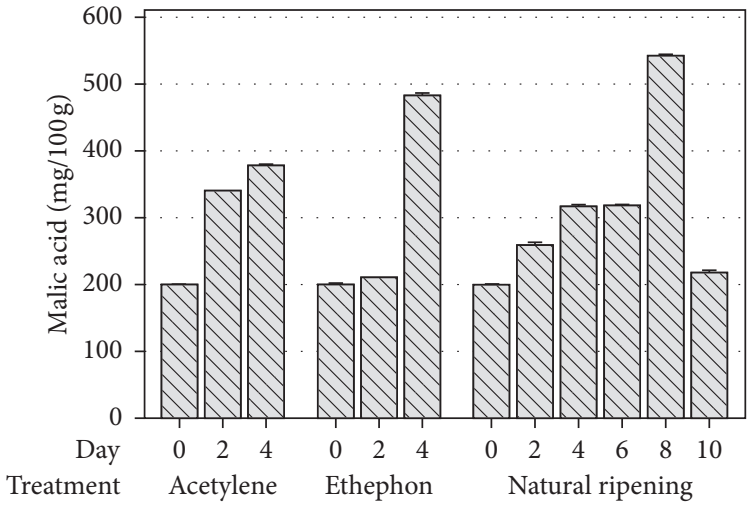

(a)

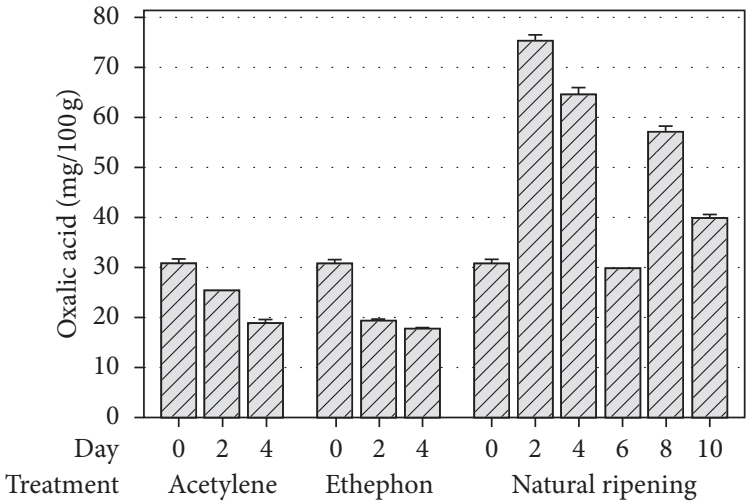

(c)

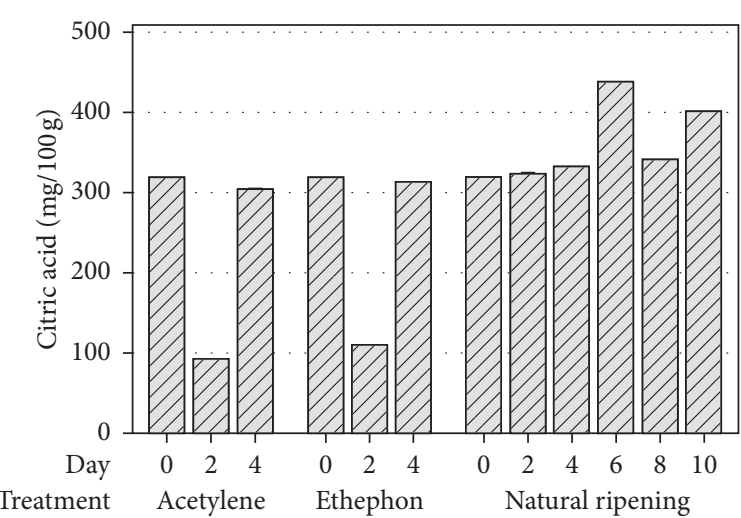

(b)

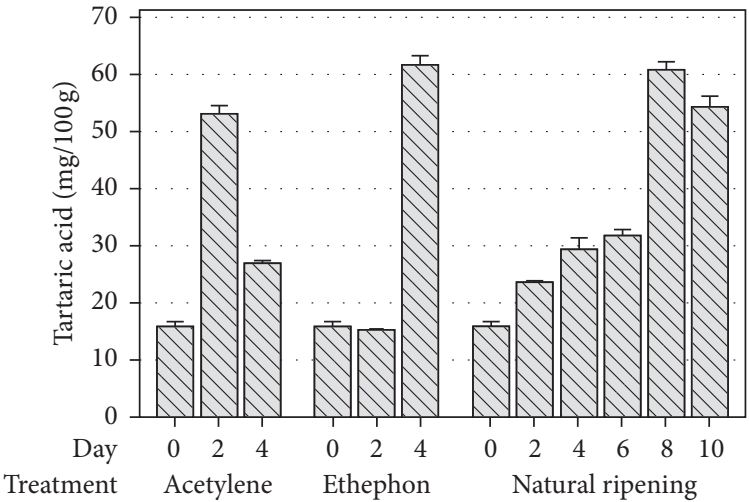

(d)

FIGURE 2: Changes of organic acid in flesh during ripening of banana treated with induced ripening agents: (a) malic acid, (b) citric acid, (c) oxalic acid, and (d) tartaric acid.

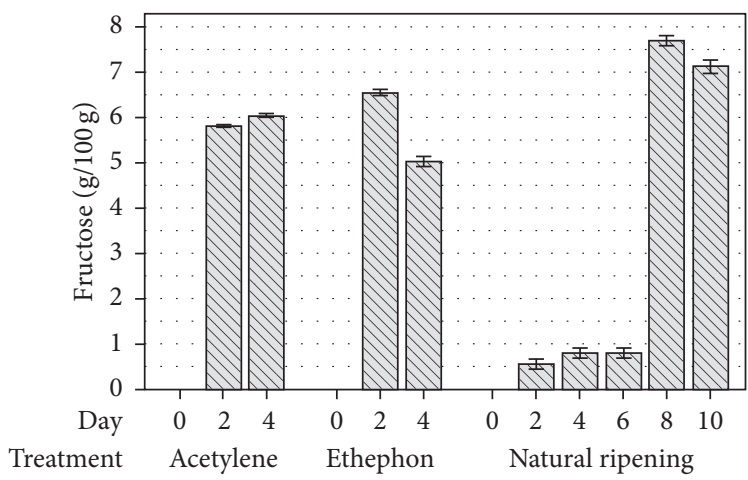

(a)

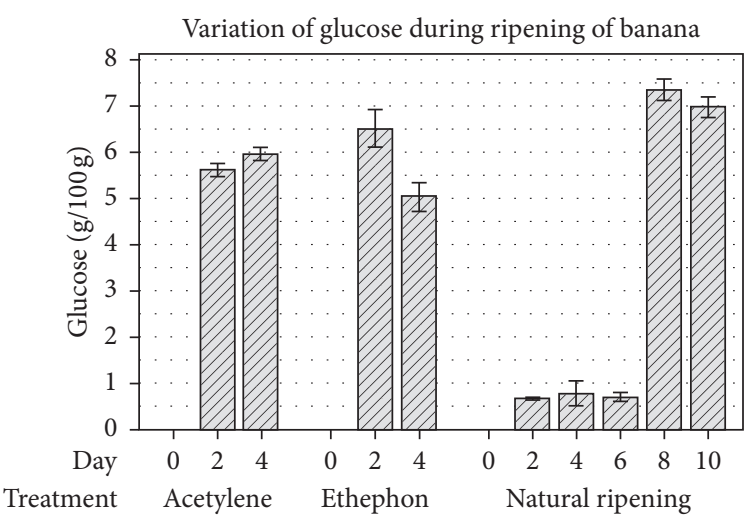

(b)

FIGURE 3: Changes of sugars in flesh during ripening of banana treated with induced ripening agents: (a) fructose and (b) glucose.

TABle 4: Fructose, glucose, maltose, and sucrose at fully yellow stage.

\begin{tabular}{lccc}
\hline Sugars & Natural ripening & Ethephon & Acetylene \\
\hline Fructose $(\mathrm{g} / 100 \mathrm{~g})$ & $7.72 \pm 0.17^{\mathrm{a}}$ & $6.55 \pm 0.11^{\mathrm{b}}$ & $5.83 \pm 0.05^{\mathrm{c}}$ \\
Glucose $(\mathrm{g} / 100 \mathrm{~g})$ & $7.37 \pm 0.33^{\mathrm{a}}$ & $6.53 \pm 0.57^{\mathrm{a}}$ & $\mathrm{ND}$ \\
Sucrose $(\mathrm{g} / 100 \mathrm{~g})$ & $1.11 \pm 0.01$ & $\mathrm{ND}$ & $\mathrm{ND}$ \\
Maltose $(\mathrm{g} / 100 \mathrm{~g})$ & $\mathrm{ND}$ & $\mathrm{ND}$ \\
\hline
\end{tabular}

Values bearing different superscript letters within the same row are statistically significant at $95 \%$ confidence level. 
stage of banana and it shows a decreasing pattern during ripening. However, according to Lizana [38], sucrose formation can be suppressed by environmental conditions mostly by high temperatures. This controversial result may be due to change in the variety of banana under the study and the high temperate weather in Sri Lanka.

As shown in Table 4, glucose and fructose contents are significantly low in acetylene-treated banana at stage 6 , which can lead to low sensory quality of fruits at eat ripe stage.

\section{Conclusion}

The present research studies the effects of ethephon and acetylene treatments as induced ripening agents on Ambul banana (Musa acuminata, AAB). Efficiency of enhancing the ripening process was found to be similar in these two agents at $1000 \mathrm{ppm}$ level. High $\mathrm{C} *$ value on peel and high firmness in flesh were recorded at fully yellow stage in acetylenetreated fruits compared to natural ripening and ethephon treatment. The results of aroma volatile analysis show that naturally ripened banana is more aromatic than treated banana as total number of volatile compounds detected was 27,16 , and 15 respectively in naturally ripened, ethephontreated, and acetylene-treated banana. The percentage of esters was very poor in acetylene-treated banana. 3-methylbutyl 3-methylbutanoate, which is responsible for fruity banana-like odour according aroma descriptions, was detected in low levels in treated fruits. Organic acid analysis shows that malic acid and citric acid were the most abundant organic acids in banana flesh. Citric acid was predominant at fully green stage, while malic acid was predominant at fully yellow stage. Citric acid, malic acid, and oxalic acid contents are significantly affected by ethephon and acetylene as those three acids were significantly high in naturally ripened bananas. Furthermore, fructose and glucose were the most available sugars in banana flesh. The ratio between fructose to glucose was close to unity in both naturally ripened and treated bananas. Sucrose was detected only in naturally ripened bananas. As well, acetylene treatment significantly lowers the glucose and fructose content in flesh. In summary, $1000 \mathrm{ppm}$ ethephon and acetylene treatment can enhance the ripening process in banana. Nevertheless, both ethephon and acetylene treatments lead to a poor aroma profile and lower levels of organic acids and sugars.

\section{Data Availability}

The numerical data supporting the findings of this paper are available from the corresponding author upon request.

\section{Conflicts of Interest}

The authors declare that there are no conflicts of interest regarding the publication of this paper.

\section{Acknowledgments}

We thank Instrument Center, Faculty of Applied Sciences, University of Sri Jayewardenepura, Sri Lanka, for providing instrument facilities. This work was supported by University Research Grants, University of Sri Jayewardenepura, Sri Lanka, under ASP/01/RE/SCI/2016/12.

\section{References}

[1] A. Lassoudière, The Banana and its Cultivation, Editions Quae, Versailles CEDEX, France, 2007.

[2] B. Singh, J. P. Singh, A. Kaur, and N. Singh, "Bioactive compounds in banana and their associated health benefits-a review," Food Chemistry, vol. 206, pp. 1-11, 2016.

[3] D. Mohapatra, S. Mishra, and N. Sutar, "Banana and its byproduct utilisation: an overview," Journal of Scientific and Industrial Research, vol. 69, pp. 323-329, 2010.

[4] S. G. Kulkarni, V. B. Kudachikar, and M. N. Keshava Prakash, "Studies on physico-chemical changes during artificial ripening of banana (Musa sp) variety 'Robusta'," Journal of Food Science and Technology, vol. 48, no. 6, pp. 730-734, 2011.

[5] A. K. Thompson and G. B. Seymour, "Comparative effects of acetylene and ethylene gas on initiation of banana ripening," Annals of Applied Biology, vol. 101, no. 2, pp. 407-410, 1982.

[6] S. D. T. Maduwanthi and R. A. U. J. Marapana, "Induced ripening agents and their effect on fruit quality of banana," International Journal of Food Science, vol. 2019, Article ID 2520179, 8 pages, 2019.

[7] N. J. S. Smith, G. B. Seymour, and A. K. Thompson, "Effects of high temperatures on the ripening responses of bananas to acetylene," Annals of Applied Biology, vol. 108, no. 3, pp. 667-672, 1986.

[8] M. W. Siddiqui and R. S. Dhua, "Eating artificially ripened fruits is harmful," Current Science, vol. 99, no. 12, pp. 16641668, 2010.

[9] M. N. Islam, M. Y. Imtiaz, S. S. Alam, F. Nowshad, S. A. Shadman, and M. S. Khan, "Artificial ripening on banana (Musa Spp.) samples: analyzing ripening agents and change in nutritional parameters," Cogent Food \& Agriculture, vol. 4, no. 1, Article ID 1477232, 2018.

[10] V. Prasanna, T. N. Prabha, and R. N. Tharanathan, "Fruit ripening phenomena-an overview," Critical Reviews in Food Science and Nutrition, vol. 47, no. 1, pp. 1-19, 2007.

[11] C. M. Sogo-Temi, O. A. Idowu, and E. Idowu, "Effect of biological and chemical ripening agents on the nutritional and metal composition of banana (Musa spp)," Journal of Applied Sciences and Environmental Management, vol. 18, no. 2, pp. 243-246, 2014.

[12] M. A. Hakim, A. K. Obidul Huq, M. A. Alam et al., "Role of health hazardous ethephone in nutritive values of selected pineapple, banana and tomato," Journal of Food, Agriculture and Environment, vol. 10, no. 2, pp. 247-251, 2012.

[13] A. S. Sonmezdag, H. Kelebek, and S. Selli, "Comparison of the aroma and some physicochemical properties of grand naine (Musa acuminata) banana as influenced by natural and ethylene-treated ripening," Journal of Food Processing and Preservation, vol. 38, no. 5, pp. 2137-2145, 2014.

[14] S. R. W. Gunasekara, K. K. G. U. Hemamali, T. G. Dayananada, and V. S. Jayamanne, "Post harvest quality analysis of embul banana following artificial ripening techniques," International Journal of Science, Environment, vol. 4, pp. 1625-1632, 2015.

[15] K. H. Sarananda, "Effect of calcium carbide on ripening of Embul banana (Musa spp.)," Tropical Agriculturist, vol. 146, 1990.

[16] Z. W. Adane, A. M. Ibrahim, D. B. Yohannes, and T. A. Welde-Meskel, "Effect of traditional kerosene smoking 
and ethrel on ripening, shelf life and quality of Cavendish banana (Musa sp.)," African Journal of Agricultural Research, vol. 10, no. 50, pp. 4570-4583, 2015.

[17] C. Bugaud and P. Alter, "Volatile and non-volatile compounds as odour and aroma predictors in dessert banana (Musa spp.)," Postharvest Biology and Technology, vol. 112, pp. 14-23, 2016.

[18] F.-X. Liu, S.-F. Fu, X.-F. Bi et al., "Physico-chemical and antioxidant properties of four mango (Mangifera indica L.) cultivars in China," Food Chemistry, vol. 138, no. 1, pp. 396-405, 2013.

[19] C. Ma, Z. Sun, C. Chen, L. Zhang, and S. Zhu, "Simultaneous separation and determination of fructose, sorbitol, glucose and sucrose in fruits by HPLC-ELSD," Food Chemistry, vol. 145, pp. 784-788, 2014.

[20] D. Mayr, T. Märk, W. Lindinger, H. Brevard, and C. Yeretzian, "Breath-by-breath analysis of banana aroma by proton transfer reaction mass spectrometry," International Journal of Mass Spectrometry, vol. 223, pp. 743-756, 2003.

[21] M. J. Jordán, K. Tandon, P. E. Shaw, and K. L. Goodner, "Aromatic profile of aqueous banana essence and banana fruit by gas chromatography-mass spectrometry (GC-MS) and gas chromatography-olfactometry (GC-O)," Journal of Agricultural and Food Chemistry, vol. 49, no. 10, pp. 48134817, 2001.

[22] J. A. Pino and Y. Febles, "Odour-active compounds in banana fruit cv. Giant Cavendish," Food Chemistry, vol. 141, no. 2, pp. 795-801, 2013.

[23] S. Vermeir, M. L. A. T. M. Hertog, K. Vankerschaver, R. Swennen, B. M. Nicolaï, and J. Lammertyn, "Instrumental based flavour characterisation of banana fruit," LWT-Food Science and Technology, vol. 42, no. 10, pp. 1647-1653, 2009.

[24] J. M. F. Nogueira, P. J. P. Fernandes, and A. M. D. Nascimento, "Composition of volatiles of banana cultivars from Madeira Island," Phytochemical Analysis, vol. 14, no. 2, pp. 87-90, 2003.

[25] G. Aurore, C. Ginies, B. Ganou-Parfait, C. M. G. C. Renard, and L. Fahrasmane, "Comparative study of free and glycoconjugated volatile compounds of three banana cultivars from French West Indies: Cavendish, Frayssinette and Plantain," Food Chemistry, vol. 129, no. 1, pp. 28-34, 2011.

[26] J. B. Golding, D. Shearer, W. B. McGlasson, and S. G. Wyllie, "Relationships between respiration, ethylene, and aroma production in ripening banana," Journal of Agricultural and Food Chemistry, vol. 47, no. 4, pp. 1646-1651, 1999.

[27] W. Batista-Silva, V. L. Nascimento, D. B. Medeiros et al., "Modifications in organic acid profiles during fruit development and ripening: correlation or causation?," Frontiers in Plant Science, vol. 9, 2018.

[28] H. Wyman and J. K. Palmer, "Organic acids in the ripening banana fruit," Plant Physiology, vol. 39, no. 4, pp. 630-633, 1964.

[29] J. U. Agravante, T. Matsui, and H. Kitagawa, "Sugars and organic acids in ethanol- and ethylene-treated banana fruits," Nippon Shokuhin Kogyo Gakkaishi, vol. 38, no. 5, pp. 441-444, 1991.

[30] P. L. Harris and G. L. Poland, "Organic acids of the ripe banana," Journal of Food Science, vol. 2, no. 2, pp. 135-142, 1937.

[31] E.-C. Pua, S. Chandramouli, P. Han, and P. Liu, "Malate synthase gene expression during fruit ripening of Cavendish banana (Musa acuminata cv. Williams)," Journal of Experimental Botany, vol. 54, no. 381, pp. 309-316, 2003.
[32] T. Y. Kheng, P. Ding, and N. A. Abdul Rahman, "Determination of optimum harvest maturity and physicochemical quality of Rastali banana (Musa AAB Rastali) during fruit ripening," Journal of the Science of Food and Agriculture, vol. 92, no. 1, pp. 171-176, 2012.

[33] G. B. Seymour, "Banana," in Biochemistry of Fruit Ripening, pp. 83-106, Springer, Dordrecht, Netherlands, 1993.

[34] K. Shimokawa, Y. Ueda, and Z. Kasai, "Decarboxylation of oxalic acid during ripening of banana fruit (Musa sapientum L.)," Agricultural and Biological Chemistry, vol. 36, no. 11, pp. 2021-2024, 1972.

[35] J. R. O. Do Nascimento, A. V. Júnior, P. Z. Bassinello et al., "Beta-amylase expression and starch degradation during banana ripening," Postharvest Biology and Technology, vol. 40, no. 1, pp. 41-47, 2006.

[36] L. d. A. Saraiva, F. P. Castelan, R. Shitakubo et al., "Black leaf streak disease affects starch metabolism in banana fruit," Journal of Agricultural and Food Chemistry, vol. 61, no. 23, pp. 5582-5589, 2013.

[37] S.-F. Yang and H.-K. Ho, "Biochemical studies on post-ripening of banana," Journal of the Chinese Chemical Society, vol. 5, no. 1-2, pp. 71-85, 1958.

[38] L. A. Lizana, "Quantitative evolution of sugars in banana fruit ripening at normal to elevated temperatures," in Proceedings of I International Symposium on Tropical and Subtropical Fruits, vol. 57, pp. 163-178, Lima, Peru, 1976. 


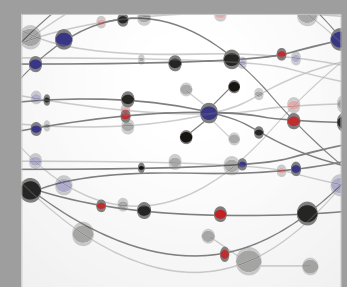

The Scientific World Journal
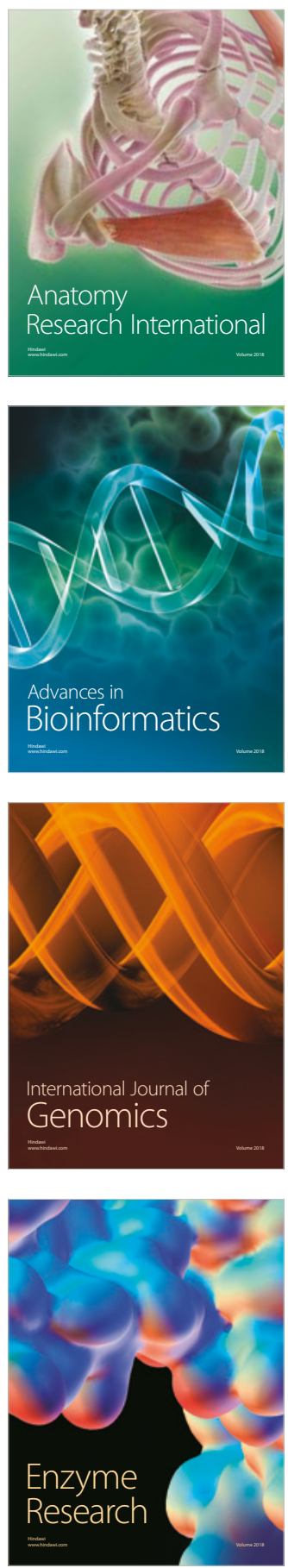
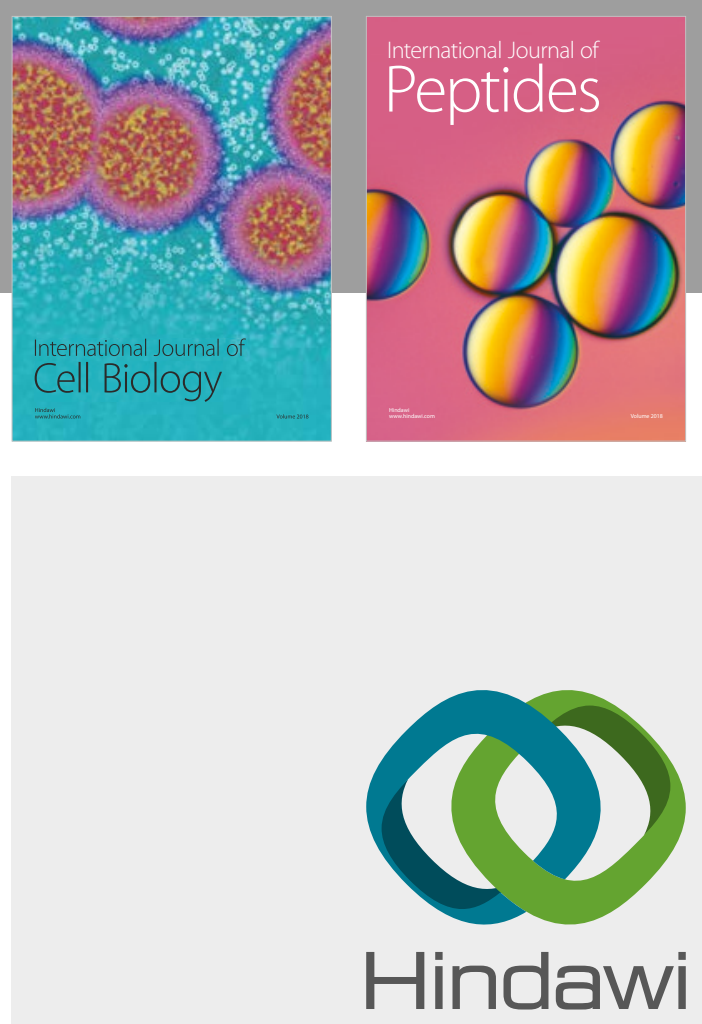

Submit your manuscripts at

www.hindawi.com
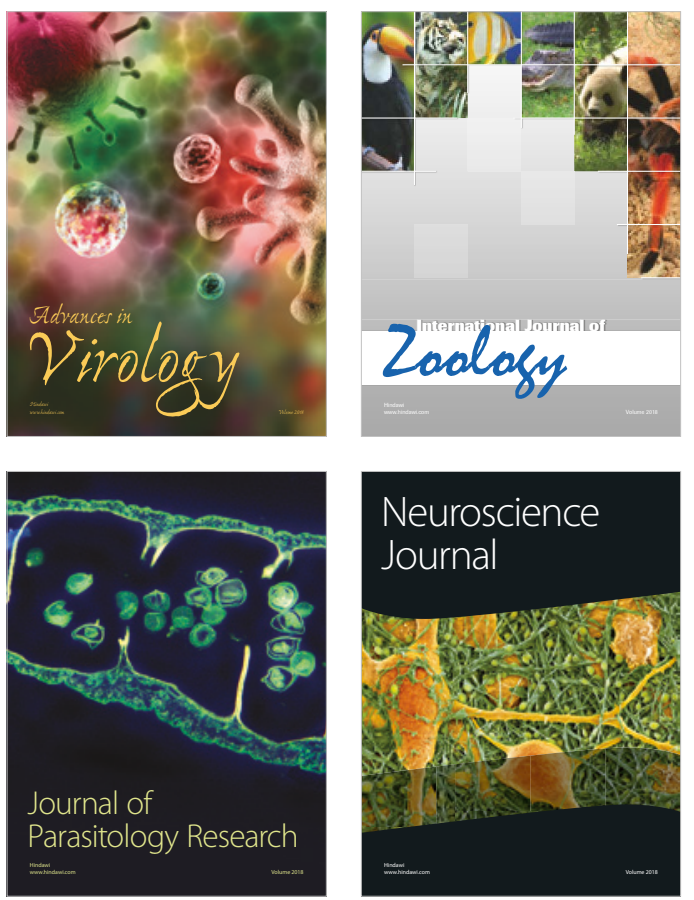
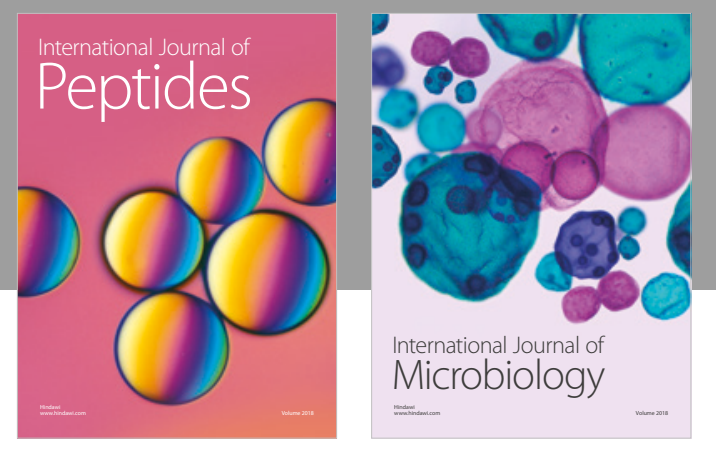

nternational Journal of Microbiology
Journal of
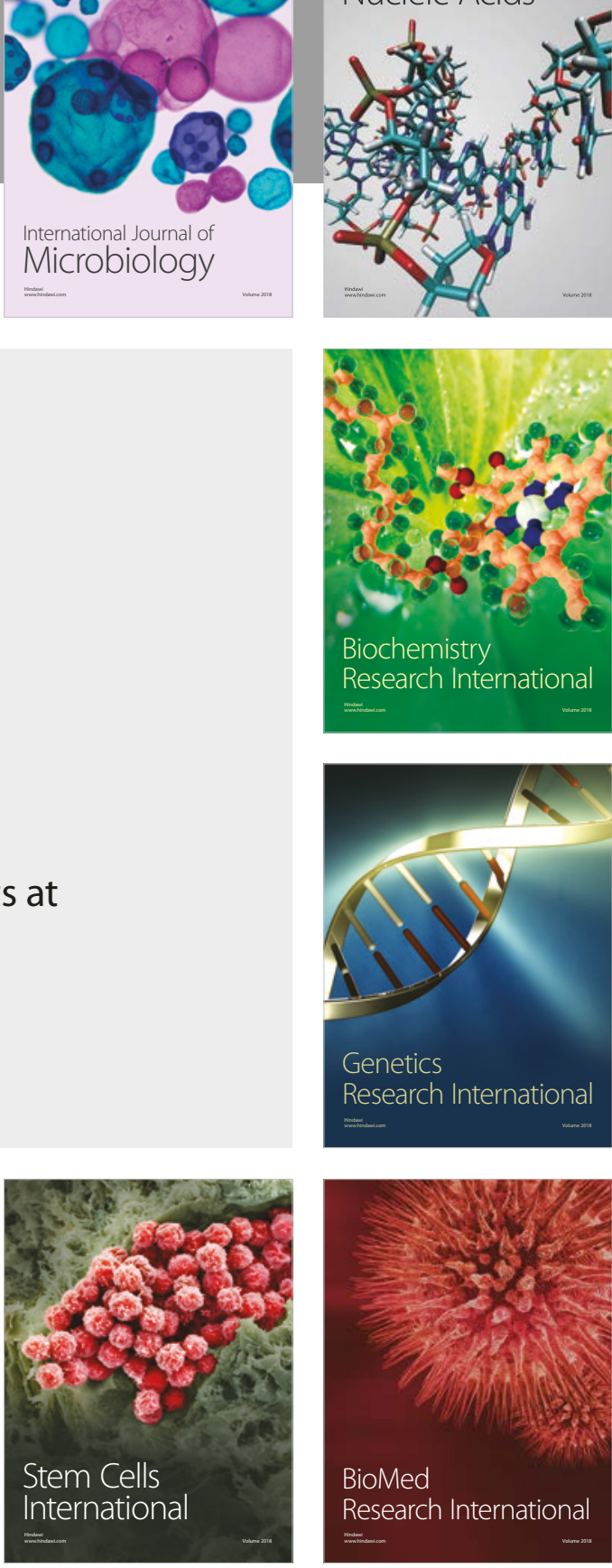
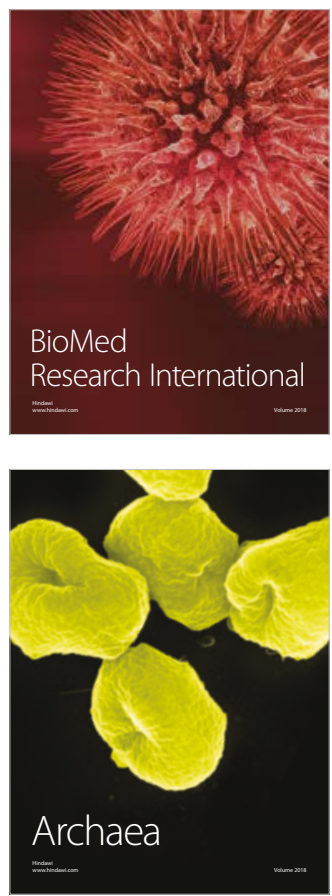